\title{
The Role of Fibrates in Primary Biliary Cholangitis
}

\author{
Christophe Corpechot ${ }^{1}$
}

Published online: 7 February 2019

(C) The Author(s) 2019

\begin{abstract}
Purpose of Review Ursodeoxycholic acid (UDCA) is recognized worldwide as the standard of care of primary biliary cholangitis (PBC). Obeticholic acid and fibrates have recently shown the potential to further improve the biochemical markers of PBC. The purpose of this review is to discuss more specifically the role of fibrates in PBC.

Recent Findings The BEZURSO trial (Phase 3 Study of Bezafibrate in Combination With Ursodeoxycholic Acid in Primary Biliary Cholangitis) is the first ever placebo-controlled trial of a fibrate in PBC. In this 24-month study, second-line use of bezafibrate in addition to continued UDCA resulted in a rate of complete biochemical response significantly higher than that achieved with placebo and UDCA. This effect was associated with a parallel improvement in symptoms and surrogate markers of fibrosis. Studies aiming to determine the effect of bezafibrate on long-term outcomes are still needed.

Summary Bezafibrate (probably fibrates in general) should be considered as a second-line therapy of PBC in patients with incomplete response to or intolerance of UDCA.
\end{abstract}

Keywords Primary biliary cholangitis $(\mathrm{PBC}) \cdot$ Fibrates $\cdot$ Bezafibrate $\cdot$ Fenofibrate $\cdot$ Peroxisome proliferator-activated receptor $(\mathrm{PPAR}) \cdot$ Clinical trial

\section{Introduction}

Primary biliary cholangitis (previously known as primary biliary cirrhosis, PBC) is a progressive cholestatic liver disease that, if untreated, ultimately leads towards cirrhosis, liver failure, and premature death [1]. PBC mainly affects middle-aged women and is characteristically associated with lesions of granulomatous, non-suppurative destructive cholangitis of small bile ducts, and detection in the serum of specific autoantibodies, mostly antimitochondrial antibodies. Inflammation and cholestasis, a defect in biliary secretion

This article is part of the Topical Collection on Autoimmune, Cholestatic, and Biliary Diseases

Christophe Corpechot

christophe.corpechot@aphp.fr

1 Reference Center for Inflammatory Biliary Diseases and Autoimmune Hepatitis, Inserm UMR_S938, Saint-Antoine Hospital \& Research Center, Assistance Publique - Hôpitaux de Paris, Sorbonne University, Paris, France leading to the accumulation of toxic bile acids within the liver, are the main driving factors of the disease. To date, however, only anticholestatic drugs have shown the potential to treat PBC, where classical or new generation anti-inflammatory drugs have failed [2].

Ursodeoxycholic acid (UDCA), a natural hydrophilic tertiary bile acid with choleretic properties, was the first anticholestatic agent to demonstrate efficiency in a phase 3 trial [3]. Accumulated evidence regarding its long-term efficacy and safety has made UDCA the only first-line treatment still recommended in PBC [4]. However, it is now clear that not all patients respond equally to UDCA and that those, approximately a third, who do not reach an adequate biochemical response are at high risk of disease progression [5-7]. Furthermore, poor tolerance to UDCA (diarrhea, abdominal pain) is reported in up to $9 \%$ of patients [8]. Two other categories of anticholestatic drugs, namely, obeticholic acid (OCA) and fibrates, were shown to be of specific interest in these situations, either in combination with UDCA or as a monotherapy $[9 \cdot \bullet, 10,11 \bullet \cdot, 12]$. The purpose of this article is to review the role of fibrates in the therapeutic management of PBC. 


\section{Fibrates: General Points}

Fibrates are an old class of lipid-lowering agents, the first representative of which, clofibrate, was discovered in 1962 after that a marked fall in serum lipids was observed in a few French farmers intoxicated by phenyl-ethyl-acetic acid, a pesticide related to this family of compounds $[13,14]$. While clofibrate was withdrawn in 2002, fenofibrate, bezafibrate, ciprofibrate, and gemfibrozil are still available for use (Table 1). Fibrates increase fatty acid oxidation and accordingly are associated with a reduction in very lowdensity lipoprotein (VLDL) production and a parallel increase in high-density lipoprotein (HDL) concentrations in plasma [15]. This is associated with a reduction in serum levels of triglycerides, a (moderate) decline in LDL-cholesterol- and a (slight) increase in HDL-cholesterol levels. These outcomes, together with inherent anti-inflammatory effects of fibrates, contribute to reduce the development of atherosclerosis [16]. Fibrate derivatives exert their effects mainly through peroxisome proliferator-activator receptor (PPAR)- $\alpha$ agonistic properties. PPARs are members of the nuclear receptor family. They are distributed in three subtypes of transcription factors designated PPAR- $\alpha$, PPAR- $\delta$, and PPAR- $\gamma$, the former isoform of which is the most strongly expressed in the liver [17]. Fibrates are major PPAR- $\alpha$ ligands, but some compounds can exhibit additional affinities for PPAR- $\delta$ and PPAR- $\gamma$. This is particularly true for bezafibrate, which is a pan-PPAR agonist.

Once absorbed, fibrates are metabolized into active acid derivatives that are extensively bound to serum albumin for transport. These metabolites, which are not dependent on the cytochrome P450 system for clearance, are predominantly excreted in the urine, but fibrate derivatives are also detected

Table 1 Fibrates: main compounds and receptor binding affinities

LIGANDS

PPAR- $\alpha$

\section{RECEPTORS}

PPAR- $\gamma$

PPAR- $\delta$

\section{CLOFIBRATE}<smiles>CCOC(=O)C(C)(C)Oc1ccc(Cl)cc1</smiles><smiles>[3H][Te]</smiles><smiles>[13CH3][TeH]</smiles>
$\mathrm{CH}_{3}$<smiles>COc1cc(C)ccc1CCC(C)(C)C(=O)O</smiles><smiles>[TeH][TeH]</smiles>

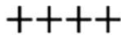
$+$<smiles>[3H][Te]</smiles> 
in the bile [18]. Most side effects related to fibrates concern potential toxicity on muscle, kidney, and liver. Rhabdomyolysis is a very rare event (combination with statin is classically discouraged), but muscle pain is a relatively common side effect. An increase in serum creatinine level is classically described. Its mechanism, which remains unclear, may involve renal hemodynamic changes or an increased release of creatinine by muscle [19]. This increase is typically mild and reversible after drug discontinuation, and no evidence for an increased risk of end-stage kidney disease has emerged from long-term studies [20-22]. Mild and transient elevation in transaminases is occasionally described in the first weeks of treatment, resolving even with continuation of the drug. Transaminase elevation above three times normal can occur in 3 to $5 \%$. Real cases of acute hepatocellular or mixed, autoimmune-like hepatitis have anecdotally been reported $[23,24]$. Finally, fibrates enhance cholesterol excretion into the bile and may consequently increase the risk of cholelithiasis [25].

\section{Fibrates in PBC: Clinical Studies}

\section{First Reports}

Clofibrate had been recognized in the 1960s for its ability to reduce the serum levels of alkaline phosphatase (ALP), but this specific property of fibrates remained largely ignored before being rediscovered in the 1990s [26, 27]. In 1999, Iwasaki et al. reported for the first time the results of an open-labeled study of bezafibrate in patients with PBC suggesting that this drug, either in combination with UDCA or alone, was safe in patients with this disease and able to decrease, or even normalize ALP and IgM levels, as well as to improve related symptoms [28]. Since then, numerous unblinded, small-sized controlled studies, first conducted in Japan and then afterwards in Western countries, have consistently confirmed these results either with bezafibrate or with fenofibrate [12, 29-37]. However, no data from placebocontrolled trials had been made available until 2017 (see next chapter on the Phase 3 study of Bezafibrate in Combination with Ursodeoxycholic Acid in Primary Biliary Cholangitis (BEZURSO) [38]. It is noteworthy that fibrates, when given as a monotherapy, have beneficial effects on ALP levels comparable in magnitude to those observed with UDCA [12]. Nowadays, it can be estimated that more than 800 patients have been exposed to bezafibrate or fenofibrate in phase 2 or 3 controlled studies. Meta-analyses of phase 2 trials have confirmed the beneficial effects of fibrates on major biochemical markers of the disease, including total bilirubin, ALP, gammaglutamyltranspeptidase (GGT), alanine aminotransferase (ALT), and IgM levels, but have failed to detect a difference in mortality, liver-related morbidity, or adverse events because of the limited size and duration of studies [39-42]. Recent data have further endorsed that partial or complete relief of itch can be reached in a significant proportion of patients with this symptom [36, 43•]. For all the above-mentioned reasons, thousands of patients around the world, notably in Japan where bezafibrate is recommended as a second-line therapy [44], are currently being treated off-label with fibrates, most often in association with UDCA. However, potential concerns remain regarding the effects of fibrates on histological progression [45], and on long-term clinical outcomes and safety, especially long-term kidney toxicity and possible worsening of liver failure in advanced cirrhotic disease [34, 37, 46]. In addition, up to $22 \%$ of patients in retrospective studies were reported to have discontinued fibrates because of side effects, mainly myalgias and abdominal pain [37]. Finally, patients with advanced fibrosis and/or severe cholestasis were shown to be less responsive to fibrate add-on therapy and to be still at risk of disease progression [43•].

\section{BEZURSO Trial}

The BEZURSO trial (Phase 3 Study of Bezafibrate in Combination with Ursodeoxycholic Acid in Primary Biliary Cholangitis, NCT01654731) is the first and currently the only available placebo-controlled trial having addressed the efficacy and safety of a fibrate in patients with PBC [11••]. This nonindustrial study randomly assigned 100 patients who had had an inadequate biochemical response to UDCA according to the Paris-2 criteria [47] (i.e., ALP or aspartate aminotransferase (AST) levels $>1.5$ times the upper limit of normal range (xULN), or elevated total bilirubin) to receive bezafibrate at a daily dose of $400 \mathrm{mg}$ (50 patients), or placebo (50 patients), in addition to continued treatment with UDCA for 24 months. Patients with decompensated cirrhosis or a total bilirubin level $>3 \mathrm{mg} / \mathrm{dL}$ and those with typical features of autoimmune hepatitis at baseline were non-eligible. The primary endpoint was the percentage of patients achieving a complete biochemical response as defined by normal levels of bilirubin, ALP, aminotransferases, albumin, and prothrombin index (a derived measure of prothrombin time) at 24 months.

The main results of the BEZURSO trial are summarized in Table 2. Half of the patients enrolled were at an advanced stage of the disease according to the histological stage (Ludwig's stage III-IV) or liver-stiffness measurement $(>9.6 \mathrm{kPa})$. Two patients $(4 \%)$ in the bezafibrate group and $6(12 \%)$ in the placebo group withdrew from the trial. The primary endpoint was achieved in $31 \%$ of the patients in the bezafibrate group and $0 \%$ in the placebo group $(p<0.001)$. At 24 months, normal levels of ALP were observed in $67 \%$ of the patients in the bezafibrate group and in $2 \%$ in the placebo group $(p<0.001)$. Changes in total bilirubin, ALP, GGT, and transaminases were consistent with the result of the primary endpoint, as were changes in pruritus, fatigue, and non-invasive markers of liver fibrosis 
Table 2 Bezafibrate vs. placebo in addition to continued UDCA in patients with primary biliary cholangitis and an inadequate response to UDCA (main results of the BEZURSO trial)

\begin{tabular}{|c|c|c|c|c|c|}
\hline \multirow[t]{2}{*}{ Outcomes } & \multicolumn{2}{|l|}{ Event rates } & \multicolumn{3}{|l|}{ At 24 months } \\
\hline & Bezafibrate & Placebo & $\mathrm{ABI}(95 \% \mathrm{CI})$ & RBI $(95 \% \mathrm{CI})$ & NNT $(95 \% \mathrm{CI})$ \\
\hline Complete response & $31 \%$ & $0 \%$ & $31 \%(18$ to 45$)$ & $2900 \%$ (84 to 48,757$)$ & $3.5(2.4$ to 6.2$)$ \\
\hline Normal ALP level & $67 \%$ & $2 \%$ & $65 \%(51$ to 79$)$ & $2730 \%(304$ to 19,733$)$ & $1.5(1.3$ to 2.0$)$ \\
\hline \multirow[t]{2}{*}{ Paris-2 response } & $70 \%$ & $10 \%$ & $60 \%$ (44 to 76$)$ & $630 \%$ (182 to 1792$)$ & $1.7(1.3$ to 2.3$)$ \\
\hline & \multicolumn{2}{|c|}{ Median change from baseline } & \multicolumn{3}{|c|}{ Difference in change from baseline $(95 \% \mathrm{CI})$} \\
\hline Total bilirubin level & $-14 \%$ & $18 \%$ & \multicolumn{3}{|c|}{$-32 \%(-47$ to -18$)$} \\
\hline ALP level & $-60 \%$ & $0 \%$ & \multicolumn{3}{|c|}{$-59 \%(-71$ to -47$)$} \\
\hline GGT level & $-38 \%$ & $7 \%$ & \multicolumn{3}{|c|}{$-45 \%(-65$ to -25$)$} \\
\hline ALT level & $-36 \%$ & $0 \%$ & \multicolumn{3}{|c|}{$-35 \%(-56$ to -14$)$} \\
\hline AST level & $-8 \%$ & $8 \%$ & \multicolumn{3}{|c|}{$-14 \%(-29$ to 0$)$} \\
\hline C4 bile acid level & $-70 \%$ & $0 \%$ & \multicolumn{3}{|c|}{$-90 \%(-178$ to -2$)$} \\
\hline Itch intensity score & $-100 \%$ & $4 \%$ & \multicolumn{3}{|c|}{$-95 \%$ ( -241 to 50$)$} \\
\hline Worsened fatigue & $8 \%$ & $36 \%$ & \multicolumn{3}{|c|}{$-28 \%(-47$ to -8$)$} \\
\hline Liver stiffness & $-15 \%$ & $22 \%$ & \multicolumn{3}{|c|}{$-36 \%(-64$ to -8$)$} \\
\hline ELF score & $-1 \%$ & $3 \%$ & \multicolumn{3}{|c|}{$-4 \%(-8$ to -1$)$} \\
\hline
\end{tabular}

$A B I$ absolute benefit increase, $R B I$ relative benefit increase, $N N T$ number needed to treat, $C I$ confidence interval

(including liver stiffness and Enhanced Liver Fibrosis score). Levels of IgM decreased by $21 \%$ in the bezafibrate group and in $2 \%$ in the placebo group, but the difference did not reach the level of significance. Patients with portal hypertension or high ALP levels at baseline were less likely to achieve an adequate response to bezafibrate. Despite improvement in biochemistries, symptoms, and surrogate markers of fibrosis in the bezafibrate group, the number of liver-related complications did not differ between treatment arms (two in each arm), thus indicating the need for longer studies to determine the effect of bezafibrate on clinical outcomes.

Regarding safety and side effects, the incidence rates of serious and non-serious adverse events were similar between treatment groups. The percentage of patients with myalgia was higher in the bezafibrate group (20\%) than in the placebo group (10\%) although the difference was not significant. A $5 \%$ significant increase in serum creatinine level at 24 months was observed in the bezafibrate group as compared to the placebo group. One patient in the bezafibrate group, who had a history of diabetes and hypertension, had a decrease in the estimated glomerular filtration rate $(e G F R)<60 \mathrm{~mL} / \mathrm{min}$. Four patients (three in the bezafibrate group and one in the placebo group) had an increase in ALT levels $>5$ times the upper limit of the normal range occurring within the first 6 months of trial. This led to a discontinuation of the active drug or placebo in three patients (two in the bezafibrate group and one in the placebo group). All cases in the bezafibrate group resolved within 3 months, either spontaneously (in one patient) or after glucocorticoid administration (two patients, in whom liver histologic features at baseline were suggestive of associated autoimmune hepatitis). No increase in the risk of cholelithiasis was reported in the bezafibrate group.

\section{Fibrates in PBC: Mechanisms of Action}

Fibrates in PBC probably act through different mechanisms commonly shared across all members of the PPAR- $\alpha$ agonists' class (Fig. 1). Some mechanisms, however, may differ depending on the fibrate concerned, with special care to bezafibrate and its additional affinities for the other two PPAR isoforms, PPAR- $\delta$ and PPAR- $\gamma$. It is important to note that PPAR- $\alpha$ is highly and mostly expressed in hepatocytes, while PPAR- $\delta$ and PPAR- $\gamma$ are present at a lower level in the liver, equally distributed in hepatocytes, cholangiocytes, Kupffer cells, and stellate cells for PPAR- $\delta$, and mainly restricted to Kupffer cells for PPAR- $\gamma$ $[17,48]$. Three main mechanisms have been suggested to account for the beneficial effects of fibrates in PBC, including the reduction of bile acid overload in liver cells, the increase of phospholipid excretion into the bile, and the inhibition of pro-inflammatory agents within the liver and biliary tree [49•]. Together, these effects would contribute to reduce cholestasis and inflammation, the two driving forces of the disease. Fibrates, indeed, repress by approximately $60 \%$ the activity of cholesterol $7 \alpha$-hydroxylase (CYP7A1), the rate-limiting enzyme in bile acid biosynthesis, thus reducing the production of bile acids in hepatocytes $[50,51]$. The results of the BEZURSO trial support this finding with a $70 \%$ reduction in the serum level of $\mathrm{C} 4$ bile 
Fig. 1 Mechanisms through which fibrates are likely to exert beneficial effects in PBC. Thick plain lines illustrate PPAR- $\alpha$ mediated effects. Thick doted lines illustrate additional effects of the pan-PPARs/PXR agonist bezafibrate. NR: nuclear receptor

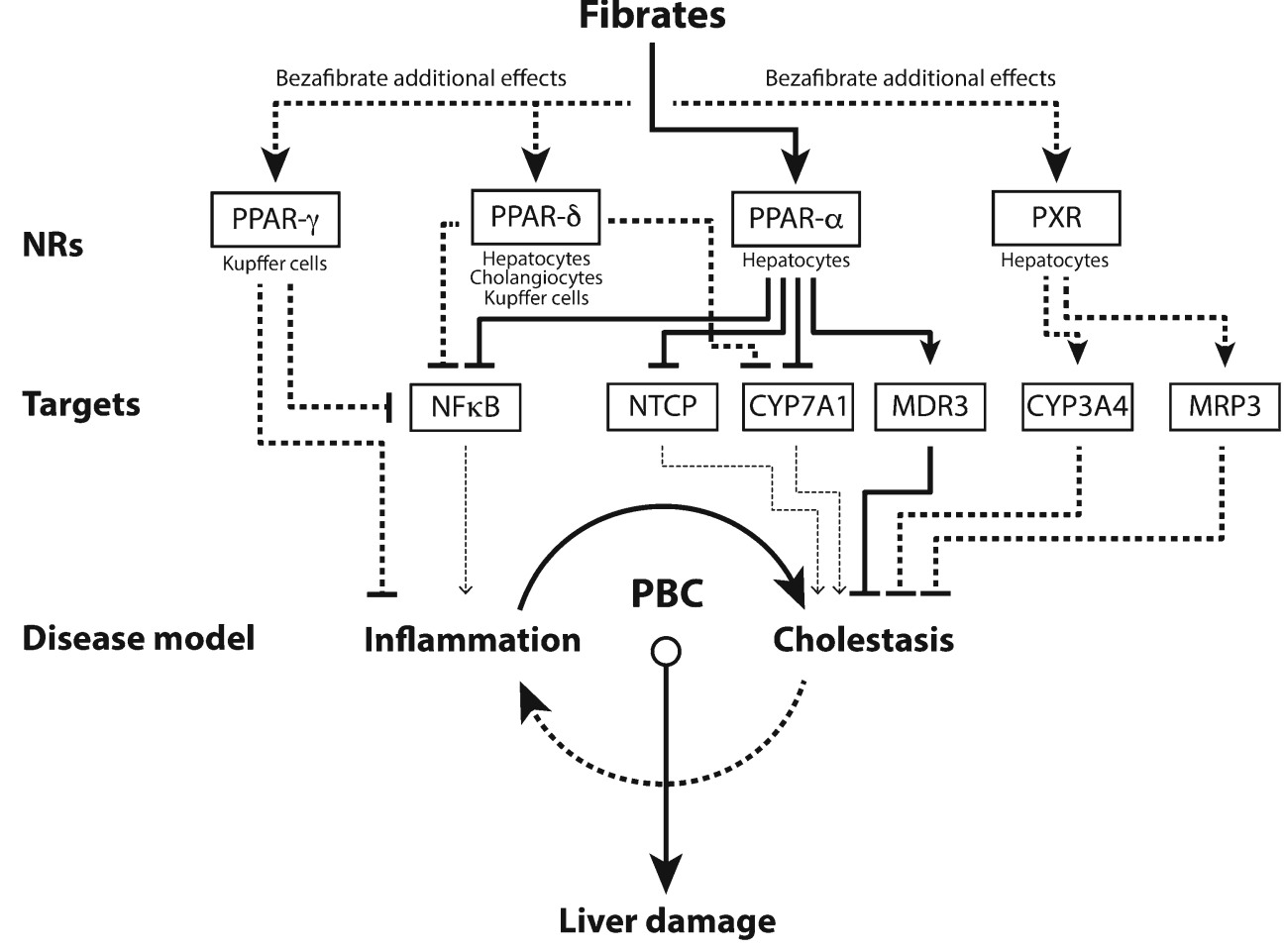

acid precursor in the bezafibrate group as compared with no change in the placebo group (Table 2) [11••]. PPAR- $\alpha$ agonists also reduce the uptake of bile acids in hepatocytes by inhibiting the expression of the basolateral transporter sodium-taurocholate-cotransporting polypeptide [52]. There is also in vitro evidence that bezafibrate, in addition to its known effects on PPARs, might induce the genes targeted by the pregnane $\mathrm{X}$ receptor (PXR), notably those involved in bile acid detoxification as CYP3A4, thus potentially acting as a dual PPAR/PXR agonist [52]. PPAR- $\alpha$ agonists also enhance the biliary output of phospholipids through transcriptional induction of the phospholipid-flippase multidrug resistance protein 3 (MDR3) [53], the consequence of which is a better protection of the hepatocytes and cholangiocytes from membrane damage caused by accumulation of toxic bile acids. Fibrates have inherent anti-inflammatory effects [54]. These effects are mediated by PPAR- $\alpha$ transrepression of NF- $\mathrm{kB}$ signaling $[55,56]$. Fibrates are therefore able to inhibit pro-inflammatory genes, and experimental models have shown that they can prevent liver inflammation [57]. As a result of its pan-PPAR properties, bezafibrate may further benefit from a broader range of therapeutic effects, including PPAR- $\delta$ - and PPAR- $\gamma$-specific anti-inflammatory actions [58, 59]. Seladelpar, a selective PPAR- $\delta$ agonist, has recently shown encouraging biochemical effects in patients with PBC [60], thus suggesting that the beneficial effects bezafibrate in PBC may partly be achieved through the activation of PPAR- $\delta$.

\section{Fibrates in PBC: Pending Questions}

New steps are certainly needed to achieve a better understanding of the actual impact of fibrates on PBC. We have learned from the BEZURSO trial that 2 years of treatment with bezafibrate, in combination with UDCA, in patients with an incomplete response to the latter drug, improve the symptoms and major biochemical markers of the disease while preventing progression in liver stiffness [11••]. Whether these effects are able to translate into a lower rate of cirrhosis development and ultimately into a better prognosis remains unknown. Longer and larger placebocontrolled trials are needed to solve this question, but these studies seem unlikely to be developed in the future without the support of industry for an old class of genericable, inexpensive drugs. The Globe and UK-PBC risk models applied to the BEZURSO data anticipated a 58\% (95\% CI: 44-73\%) and $51 \%$ (95\% CI: $32-71 \%$ ) reduction, respectively in the 10 -year risk of death or liver transplantation in bezafibrate- vs. placebotreated patients $[11 \bullet \cdot$. Long-term side effects and safety of fibrates in $\mathrm{PBC}$ require prospective longitudinal studies with a special attention paid to kidney and to cirrhotic patients.

Other pending questions include the strategic positioning of fibrates with respect to OCA in the management of patients with PBC and incomplete response or intolerance to UDCA, as well as the potential synergy of fibrates with OCA in treating PBC. There is currently no available data providing direct comparison between these two drug regimens. Unlike OCA, bezafibrate is still off-label for use in PBC. However, the comparison of the 
efficacy, safety, side-effect, and cost profiles of the two drugs, when taken together, is rather in favor of bezafibrate. Bezafibrate is furthermore the only one of the two therapies with a proven beneficial effect on PBC-validated surrogate markers of liver fibrosis. Fibrates, at last, are available in many countries in which OCA is not obtainable. Therefore, treating PBC with fibrates (preferably bezafibrate) as second-line use, either in addition to (inadequate response) or in substitution of (intolerance) UDCA, might reasonably be advocated, followed by OCA as a third-line option if available in case of incomplete response to or poor tolerance of fibrates. In patients with poor response to either dual (UDCA-OCA or UDCA-fibrates) therapy, pilot studies of triple (UDCA-OCA-fibrates) therapy are required to assess the potential synergy of OCA with fibrates. Finally, UDCA and fibrate combo therapy as first-line use in treatment-naive patients would deserve further consideration in future clinical trials.

\section{Conclusions}

We have now three major players in PBC treatment, namely, UDCA as a standard of care, followed by OCA and off-label use of bezafibrate as second-line options. Bezafibrate, or fibrates in general, has shown the potential to reduce symptoms and biochemical features of cholestasis in PBC, either in association with UDCA or alone. In patients with an incomplete response to UDCA, add-on therapy with bezafibrate further prevents progression in surrogate markers of fibrosis. Myalgia is a common but generally well-tolerated side effect of fibrates. Serum creatinine should be monitored during treatment, as should be transaminases more specifically within the first 6 months of treatment. Long-term outcomes of fibrates in patients with $\mathrm{PBC}$ require further evaluation.

\section{Compliance with Ethical Standards}

Conflicts of Interest The author reports receiving consulting fees from Intercept and Inventiva, grant support from Arrow Génériques (rAF 13.022_BeZUrSO_P100109_NVAL 2013/2011-078-02), Intercept and French Ministry of Health(PHRC 2010 (BEZURSO; P100109), and fees for teaching from GlaxoSmithKline.

Human and Animal Rights Statement All reported studies/experiments with human or animal subjects performed by the authors have been previously published and complied with all applicable ethical standards (including the Helsinki declaration and its amendments, institutional/ national research committee standards, and international/national/institutional guidelines).

Informed Consent Informed consent was obtained in all participants in the BEZURSO trial.

Open Access This article is distributed under the terms of the Creative Commons Attribution 4.0 International License (http:// creativecommons.org/licenses/by/4.0/), which permits unrestricted use, distribution, and reproduction in any medium, provided you give appropriate credit to the original author(s) and the source, provide a link to the Creative Commons license, and indicate if changes were made.

Publisher's Note Springer Nature remains neutral with regard to jurisdictional claims in published maps and institutional affiliations.

\section{References}

Papers of particular interest, published recently, have been highlighted as:

- Of importance

•. Of major importance

1. Carey EJ, Ali AH, Lindor KD. Primary biliary cirrhosis. Lancet. 2015;386:1565-75.

2. Molinaro A, Marschall HU. Why doesn't primary biliary cholangitis respond to immunosuppressive medications? Curr Hepatol Rep. 2017;16:119-23.

3. Poupon RE, Balkau B, Eschwege E, Poupon R. A multicenter, controlled trial of ursodiol for the treatment of primary biliary cirrhosis. N Engl J Med. 1991;324:1548-54.

4. EASL Clinical Practice Guidelines. The diagnosis and management of patients with primary biliary cholangitis. J Hepatol. 2017;67: 145-72.

5. Pares A, Caballeria L, Rodes J. Excellent long-term survival in patients with primary biliary cirrhosis and biochemical response to ursodeoxycholic acid. Gastroenterology. 2006;130:715-20.

6. Corpechot C, Abenavoli L, Rabahi N, Chretien Y, Andreani T, Johanet $\mathrm{C}$, et al. Biochemical response to ursodeoxycholic acid and long-term prognosis in primary biliary cirrhosis. Hepatology. 2008;48:871-7.

7. Lammers WJ, van Buuren HR, Hirschfield GM, Janssen HL, Invernizzi P, Mason AL, et al. Levels of alkaline phosphatase and bilirubin are surrogate end points of outcomes of patients with primary biliary cirrhosis: an international follow-up study. Gastroenterology. 2014;147:1338-49.

8. Hempfling W, Dilger K, Beuers U. Systematic review: ursodeoxycholic acid-adverse effects and drug interactions. Aliment Pharmacol Ther. 2003;18:963-72.

9.• Nevens F, Andreone P, Mazzella G, Strasser SI, Bowlus C, Invernizzi $\mathrm{P}$, et al. A placebo-controlled trial of obeticholic acid in primary biliary cholangitis. N Engl J Med. 2016;375:631-43 First placebo-controlled phase 3 trial of obeticholic acid, a selective FXR agonist, in primary biliary cholangitis.

10. Kowdley KV, Luketic V, Chapman R, Hirschfield GM, Poupon R, Schramm C, et al. A randomized trial of obeticholic acid monotherapy in patients with primary biliary cholangitis. Hepatology. 2018;67:1890-902.

11.• Corpechot C, Chazouilleres O, Rousseau A, Le Gruyer A, Habersetzer F, Mathurin P, et al. A placebo-controlled trial of bezafibrate in primary biliary cholangitis. N Engl J Med. 2018;378:2171-81 First and currently only available placebocontrolled phase 3 trial of a fibrate (bezafibrate, pan-PPAR agonist) in primary biliary cholangitis.

12. Iwasaki S, Ohira H, Nishiguchi S, Zeniya M, Kaneko S, Onji M, et al. The efficacy of ursodeoxycholic acid and bezafibrate combination therapy for primary biliary cirrhosis: a prospective, multicenter study. Hepatol Res. 2008;38:557-64.

13. Redel J, Cottet J. Hypocholesterolemizing effect of some disubstituted acetic acids. C R Hebd Seances Acad Sci. 1953;236:2553-5. 
14. Thorp JM, Waring WS. Modification of metabolism and distribution of lipids by ethyl chlorophenoxyisobutyrate. Nature. 1962;194: 948-9.

15. Staels B, Dallongeville J, Auwerx J, Schoonjans K, Leitersdorf E, Fruchart JC. Mechanism of action of fibrates on lipid and lipoprotein metabolism. Circulation. 1998;98:2088-93.

16. Lalloyer F, Staels B. Fibrates, glitazones, and peroxisome proliferator-activated receptors. Arterioscler Thromb Vasc Biol. 2010;30:894-9.

17. Willson TM, Brown PJ, Sternbach DD, Henke BR. The PPARs: from orphan receptors to drug discovery. J Med Chem. 2000;43: 527-50.

18. Raedsch R, Plachky J, Wolf N, Simonis G. Biliary lipids, lithogenic index and biliary drug concentrations during etofibrate and bezafibrate treatment. Eur J Drug Metab Pharmacokinet. 1995;20: 113-8.

19. Sica DA. Fibrate therapy and renal function. Curr Atheroscler Rep. 2009; $11: 338-42$

20. Jun M, Zhu B, Tonelli M, Jardine MJ, Patel A, Neal B, et al. Effects of fibrates in kidney disease: a systematic review and meta-analysis. J Am Coll Cardiol. 2012;60:2061-71.

21. Zhao YY, Weir MA, Manno M, Cordy P, Gomes T, Hackam DG, et al. New fibrate use and acute renal outcomes in elderly adults: a population-based study. Ann Intern Med. 2012;156:560-9.

22. Mychaleckyj JC, Craven T, Nayak U, Buse J, Crouse JR, Elam M, et al. Reversibility of fenofibrate therapy-induced renal function impairment in ACCORD type 2 diabetic participants. Diabetes Care. 2012;35:1008-14.

23. Ahmad J, Odin JA, Hayashi PH, Chalasani N, Fontana RJ, Barnhart $\mathrm{H}$, et al. Identification and characterization of fenofibrate-induced liver injury. Dig Dis Sci. 2017;62:3596-604.

24. Homberg JC, Abuaf N, Helmy-Khalil S, Biour M, Poupon R, Islam $\mathrm{S}$, et al. Drug-induced hepatitis associated with anticytoplasmic organelle autoantibodies. Hepatology. 1985;5:722-7.

25. Summerfield JA, Elias E, Sherlock S. Effects of clofibrate in primary biliary cirrhosis hypercholesterolemia and gallstones. Gastroenterology. 1975;69:998-1000.

26. Hellman L, Zumoff B, Kessler G, Kara E, Rubin IL, Rosenfeld RS. Reduction of cholesterol and lipids in man by ethyl Pchlorophenoxyisobutyrate. Ann Intern Med. 1963;59:477-94.

27. Day AP, Feher MD, Chopra R, Mayne PD. The effect of bezafibrate treatment on serum alkaline phosphatase isoenzyme activities. Metabolism. 1993;42:839-42.

28. Iwasaki S, Tsuda K, Ueta H, Aono R, Ono M, Saibara T, et al. Bezafibrate may have a beneficial effect in pre-cirrhotic primary biliary cirrhosis. Hepatol Res. 1999;16:12-8.

29. Nakai S, Masaki T, Kurokohchi K, Deguchi A, Nishioka M. Combination therapy of bezafibrate and ursodeoxycholic acid in primary biliary cirrhosis: a preliminary study. Am J Gastroenterol. 2000;95:326-7.

30. Kurihara T, Niimi A, Maeda A, Shigemoto M, Yamashita K. Bezafibrate in the treatment of primary biliary cirrhosis: comparison with ursodeoxycholic acid. Am J Gastroenterol. 2000;95: 2990-2.

31. Kurihara T, Maeda A, Shigemoto M, Yamashita K, Hashimoto E. Investigation into the efficacy of bezafibrate against primary biliary cirrhosis, with histological references from cases receiving long term monotherapy. Am J Gastroenterol. 2002;97:212-4.

32. Ohira H, Sato Y, Ueno T, Sata M. Fenofibrate treatment in patients with primary biliary cirrhosis. Am J Gastroenterol. 2002;97:21479

33. Ohmoto K, Yoshioka N, Yamamoto S. Long-term effect of bezafibrate on parameters of hepatic fibrosis in primary biliary cirrhosis. J Gastroenterol. 2006;41:502-3.

34. Hosonuma K, Sato K, Yamazaki Y, Yanagisawa M, Hashizume H, Horiguchi N, et al. A prospective randomized controlled study of long-term combination therapy using ursodeoxycholic acid and bezafibrate in patients with primary biliary cirrhosis and dyslipidemia. Am J Gastroenterol. 2015;110:423-31.

35. Levy C, Peter JA, Nelson DR, Keach J, Petz J, Cabrera R, et al. Pilot study: fenofibrate for patients with primary biliary cirrhosis and an incomplete response to ursodeoxycholic acid. Aliment Pharmacol Ther. 2011;33:235-42.

36. Lens S, Leoz M, Nazal L, Bruguera M, Pares A. Bezafibrate normalizes alkaline phosphatase in primary biliary cirrhosis patients with incomplete response to ursodeoxycholic acid. Liver Int. 2014;34:197-203.

37. Cheung AC, Lapointe-Shaw L, Kowgier M, Meza-Cardona J, Hirschfield GM, Janssen HL, et al. Combined ursodeoxycholic acid (UDCA) and fenofibrate in primary biliary cholangitis patients with incomplete UDCA response may improve outcomes. Aliment Pharmacol Ther. 2016;43:283-93.

38. Corpechot C, Chazouillères O, Rousseau A, Guyader D, Habersetzer F, Mathurin P, et al. A 2-year multicenter, doubleblind, randomized, placebo-controlled study of bezafibrate for the treatment of primary biliary cholangitis in patients with inadequate biochemical response to ursodeoxycholic acid therapy (Bezurso). J Hepatol. 2017;66:S89.

39. Grigorian AY, Mardini HE, Corpechot C, Poupon R, Levy C. Fenofibrate is effective adjunctive therapy in the treatment of primary biliary cirrhosis: a meta-analysis. Clin Res Hepatol Gastroenterol. 2015;39:296-306.

40. Zhang Y, Chen K, Dai W, Xia Y, Wang F, Shen M, et al. Combination therapy of bezafibrate and ursodeoxycholic acid for primary biliary cirrhosis: a meta-analysis. Hepatol Res. 2015;45: $48-58$.

41. Rudic JS, Poropat G, Krstic MN, Bjelakovic G, Gluud C. Bezafibrate for primary biliary cirrhosis. Cochrane Database Syst Rev. 2012;1:CD009145.

42. Zhang Y, Li S, He L, Wang F, Chen K, Li J, et al. Combination therapy of fenofibrate and ursodeoxycholic acid in patients with primary biliary cirrhosis who respond incompletely to UDCA monotherapy: a meta-analysis. Drug Des Devel Ther. 2015;9: 2757-66.

43. Reig A, Sese P, Pares A. Effects of bezafibrate on outcome and pruritus in primary biliary cholangitis with suboptimal ursodeoxycholic acid response. Am J Gastroenterol. 2018;113: 49-55 First longitudinal study suggesting a significant benefical effect of bezafibrate on pruritus in primary biliary cholangitis.

44. Working Subgroup for Clinical Practice Guidelines for Primary Biliary C. Guidelines for the management of primary biliary cirrhosis: the Intractable Hepatobiliary Disease Study Group supported by the Ministry of Health, Labour and Welfare of Japan. Hepatol Res. 2014;44(Suppl S1):71-90.

45. Yano K, Kato H, Morita S, Takahara O, Ishibashi H, Furukawa R. Is bezafibrate histologically effective for primary biliary cirrhosis? Am J Gastroenterol. 2002;97:1075-7.

46. Jones DE, Hansen BE. Editorial: fenofibrate as second-line therapy in high risk $\mathrm{PBC}$-more answers or more questions? Aliment Pharmacol Ther. 2016;43:648-9.

47. Corpechot C, Chazouilleres O, Poupon R. Early primary biliary cirrhosis: biochemical response to treatment and prediction of long-term outcome. J Hepatol. 2011;55:1361-7.

48. Gonzalez-Sanchez E, Firrincieli D, Housset C, Chignard N. Expression patterns of nuclear receptors in parenchymal and nonparenchymal mouse liver cells and their modulation in cholestasis. Biochim Biophys Acta. 1863;2017:1699-708.

49. Ghonem NS, Assis DN, Boyer JL. Fibrates and cholestasis. Hepatology. 2015;62:635-43 Important systematic review depicting the reported effects and potential mechanisms of fibrates in cholestatic liver disease. 
50. Stahlberg D, Reihner E, Rudling M, Berglund L, Einarsson K, Angelin B. Influence of bezafibrate on hepatic cholesterol metabolism in gallstone patients: reduced activity of cholesterol 7 alphahydroxylase. Hepatology. 1995;21:1025-30.

51. Post SM, Duez H, Gervois PP, Staels B, Kuipers F, Princen HM. Fibrates suppress bile acid synthesis via peroxisome proliferatoractivated receptor-alpha-mediated downregulation of cholesterol 7 alpha-hydroxylase and sterol 27-hydroxylase expression. Arterioscler Thromb Vasc Biol. 2001;21:1840-5.

52. Honda A, Ikegami T, Nakamuta M, Miyazaki T, Iwamoto J, Hirayama T, et al. Anticholestatic effects of bezafibrate in patients with primary biliary cirrhosis treated with ursodeoxycholic acid. Hepatology. 2013;57:1931-41.

53. Chianale J, Vollrath V, Wielandt AM, Amigo L, Rigotti A, Nervi F, et al. Fibrates induce mdr2 gene expression and biliary phospholipid secretion in the mouse. Biochem J. 1996;314(Pt 3):781-6.

54. Straus DS, Glass CK. Anti-inflammatory actions of PPAR ligands: new insights on cellular and molecular mechanisms. Trends Immunol. 2007;28:551-8.

55. Delerive P, De Bosscher K, Besnard S, Vanden Berghe W, Peters JM, Gonzalez FJ, et al. Peroxisome proliferator-activated receptor alpha negatively regulates the vascular inflammatory gene response by negative cross-talk with transcription factors NF-kappaB and AP-1. J Biol Chem. 1999;274:32048-54.

56. Staels B, Koenig W, Habib A, Merval R, Lebret M, Torra IP, et al. Activation of human aortic smooth-muscle cells is inhibited by
PPARalpha but not by PPARgamma activators. Nature. 1998;393: 790-3.

57. Nagasawa T, Inada Y, Nakano S, Tamura T, Takahashi T, Maruyama K, et al. Effects of bezafibrate, PPAR pan-agonist, and GW501516, PPARdelta agonist, on development of steatohepatitis in mice fed a methionine- and choline-deficient diet. Eur J Pharmacol. 2006;536:182-91.

58. Nozaki Y, Harada K, Sanzen T, Nakanuma Y. PPARgamma ligand attenuates portal inflammation in the MRL-lpr mouse: a new strategy to restrain cholangiopathy in primary biliary cirrhosis. Med Mol Morphol. 2013;46:153-9.

59. Haczeyni F, Wang H, Barn V, Mridha AR, Yeh MM, Haigh WG, et al. The selective peroxisome proliferator-activated receptor-delta agonist seladelpar reverses nonalcoholic steatohepatitis pathology by abrogating lipotoxicity in diabetic obese mice. Hepatol Commun. 2017;1:663-74.

60. Jones D, Boudes PF, Swain MG, Bowlus CL, Galambos MR, Bacon BR, et al. Seladelpar (MBX-8025), a selective PPAR-delta agonist, in patients with primary biliary cholangitis with an inadequate response to ursodeoxycholic acid: a double-blind, randomised, placebo-controlled, phase 2, proof-of-concept study. Lancet Gastroenterol Hepatol. 2017;2:716-26 First phase 2 trial suggesting a beneficial effect of deladelpar, a selective PPARdelta agonist, in primary biliary cholangitis. 